\title{
Effect of Beverages on the In Vitro Disintegration of Immediate-Release Pain Medications
}

\author{
Monica C. Chuong ${ }^{1 *}$, Catherine A. Taglieri ${ }^{1}$, \\ Steven J. Crosby' ${ }^{1}$, Joe W. Ferullo ${ }^{1}$, and Pitwei $\mathbf{~ g ~}^{2}$ \\ 'School of Pharmacy, Boston, Massachusetts College of Pharmacy and Health Sciences, 179 Longwood Ave, Boston, MA 02115 \\ ${ }^{2} S$ chool of Pharmacy, National University of Singapore
}

\begin{abstract}
This study compared the disintegration times of three immediate-release pain-relief tablets, ibuprofen (200 mg), tramadol $\mathrm{HCl}(50 \mathrm{mg})$, and hydrocodone bitartrate-acetaminophen $(5 \mathrm{mg} / 500 \mathrm{mg}$ ), in different beverages (milk, calcium-fortified orange juice, commercial iced coffee, and regular Coca-Cola) with those in water using the USP disintegration apparatus. A hybrid medium prepared by blending $640 \mathrm{~mL}$ fat-free or $2 \%$ milk at $5.0 \pm 1.0^{\circ} \mathrm{C}$ with $160 \mathrm{~mL}$ of $0.1 \mathrm{~N}$ hydrochloric acid $(\mathrm{HCl})$ at $39.0 \pm 0.5^{\circ} \mathrm{C}$ was proposed to better mimic human gastric content after tablet ingestion. The hybrid preparation was then used as the medium in USP dissolution Apparatus 2 to test these pain medications. The results show that the delay of the hydrocodone bitartrate-acetaminophen tablet disintegration in the hybrid media was less extensive than in straight milk (16.46 $\pm 0.65 \mathrm{~min}, n=3$ versus $31.94 \pm 2.26 \mathrm{~min}, n=6$ when fat-free milk was used). Significant foam formed in both straight and hybrid fat-free milk. There was less foaming when the same tests were conducted in the USP dissolution apparatus. The ascending and descending motion of a USP disintegration apparatus may facilitate ambient air contact with fat-free milk, resulting in foam formation. If also true in vivo, it reflects a potential problem of hindered drug absorption.
\end{abstract}

\section{INTRODUCTION}

( ral solid dosage forms such as tablets and hard-gelatin capsules, which have been in existence since the nineteenth century, remain the most frequently used dosage forms today. Tablets and capsules accounted for about half of the 579 new medicines licensed from 1995 to 1999 (221 were in tablet dosage form and 51 in capsule form) (1). A tablet that can withstand the stresses of subsequent packaging operations and reach the patient in an acceptable condition is generally assessed by friability and hardness tests. Disintegration is an important physical property of a tablet dosage form during the research and development stage and is most commonly studied in either water or simulated gastric medium and occasionally in simulated intestinal medium. However, patients do take medications with beverages other than water. Often patients are counseled to take medications, especially pain-relief medications, with milk to decrease the potential for gastric irritation.

Chuong et al. (2) studied the disintegration of TriCor (fenofibrate tablets, $54 \mathrm{mg}$, Abbott) in different beverages and found that there was a delayed disintegration of TriCor in fat-free milk and $2 \%$ milk compared with that in water (19.82 $\pm 1.82 \mathrm{~min}$ and $21.69 \pm 0.41 \mathrm{~min}$, respectively, versus $12.06 \pm 0.11 \mathrm{~min})$. But TriCor is a lipid-regulating agent. A delay of 7-10 min may not result in a significant

${ }^{*}$ Corresponding author. clinical impact on the therapeutic outcome. In addition, the delay observed in TriCor disintegration may not occur in other pharmaceutical products because the excipients and formulation procedures are all varied. For example, the bioavailability of ibuprofen, a pain-relief active ingredient, is similar among the different oral dosage forms at approximately $80 \%$, but the time to reach peak concentration differs and is roughly 120 min after tablet administration. Administration of oral products immediately following a meal has a minimal effect on overall bioavailability; however, it decreases the maximal concentration, $C_{\max }$ and the time to reach maximal concentration, $T_{\max }$ (3).

Since the pharmaceutical design of an immediaterelease (IR) oral pain medication is expected to release drug substance instantaneously and take action on pain control after ingestion, the in vitro disintegration time is also expected to be short. Therefore, the project had the following objectives: (1) to investigate whether the disintegration time of an IR pain medication tablet in beverages such as milk, commercial iced coffee, calcium-fortified orange juice, or regular Coca-Cola would be the same as in water; (2) to evaluate the effect of simulated food weight on the disintegration time of the model products; and (3) to examine whether a straight beverage was appropriate for conducting such an experiment or a better medium preparation should be proposed and examined. The same medium preparation would then be used to test model drug products in USP dissolution Apparatus 2. 


\section{MATERIALS AND METHODS \\ Materials}

Hydrochloric acid (36.5-38.0\%) was purchased from VWR. An Acurite timer was obtained from a local store.

\section{Commercial Tablet Model Dosage Forms}

Three IR pain-relief tablets were chosen as study products. Tramadol HCl 50-mg tablets (Mylan Pharmaceuticals Inc., Morgantown, WV; Lot: 3000990 , Exp. Sep 2009; total tablet weight $188.2 \pm 1.8 \mathrm{mg}, n=3$ ), ibuprofen 200-mg tablets (Ivax by Teva, North Wales, PA; Lot: P49749, Exp. Feb 2010; total tablet weight 339.4 \pm 3.7 $\mathrm{mg}, n=3$ ), and hydrocodone bitartrate-acetaminophen tablets, USP, 5 mg/500 mg (Mallinckrodt Inc., St. Louis, MO; Lot: 0357M64266, Exp. March 2012; total tablet weight $634.1 \pm 6.6 \mathrm{mg}, n=3$ ) were purchased from Cardinal Health. Among the three study products, only ibuprofen has an orange/brown colorant coat (Figure 1).

\section{Study Media}

Fat-free, $1 \%, 2 \%$, and $4 \%$ milk fortified with vitamins $A$ and D (products of Garelick Farms Inc., Franklin, MA), regular Coca-Cola, and calcium-fortified orange juice (Tropicana Pure Premium, no pulp, Florida) were obtained from two different local stores, while commercial iced coffee was purchased from a local McDonald's restaurant on different occasions.

\section{Methods}

Each of the three study pain medication tablets was dropped into one basket tube of the USP disintegration apparatus and loaded into a one-liter, low-form glass beaker filled with $800 \mathrm{~mL}$ of $5.0 \pm 1.0^{\circ} \mathrm{C}$ deionized water (to mimic refrigerated temperature), then lowered into a bath containing $8.5 \mathrm{~L}$ of water. The temperature of the bath was maintained at $39.0 \pm 1.0^{\circ} \mathrm{C}$ throughout the entire test period. The apparatus was calibrated based on the guideline of USP 31-NF 27 (4) to ensure that the basket ascended and descended in an immersion fluid at 29-32 cycles per minute until the tablet was completely disintegrated and fragments fell out of the stainless steel

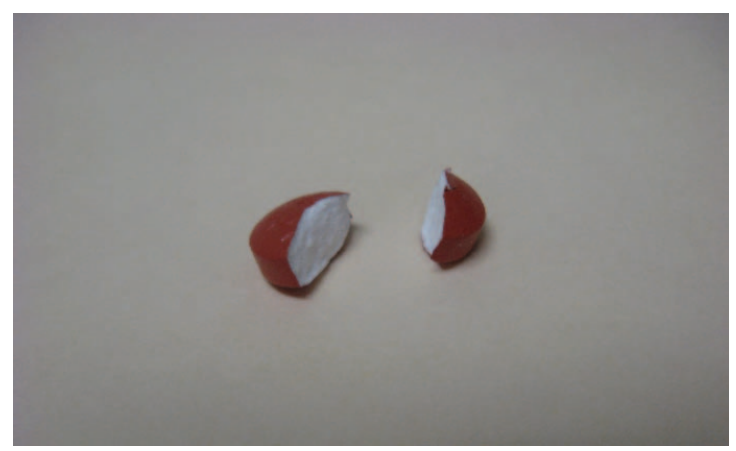

Figure 1. Photograph of ibuprofen 200-mg tablet, product of Ivax by Teva, showing external colorant coat. mesh. The disintegration time was then recorded. To study the food-weight effect as a disintegration parameter, the tested pain medication was laid on the mesh of a basket tube. A USP disk weighing $3.05 \mathrm{~g}$ was then placed flat on top of the tablet. The experiment was conducted the same as above. In addition to the use of deionized water, fat-free, $1 \%, 2 \%$, and $4 \%$ milk, calcium-fortified orange juice, commercial iced coffee, and regular Coca-Cola were chosen as immersion media to study the beverage effect on tablet disintegration time.

\section{Statistical Analysis}

Excel 2000 (Microsoft) was used to manage raw data. Using SigmaPlot 11 Exact Graphs and Data Analysis (Systat Software Inc., San Jose, CA), independent $t$-test and one-way ANOVA were performed for two-group data and three-group data analysis when normality and equal variance met. A pairwise multiple comparison procedure (Tukey Test) was selected as the posthoc test (5). The rank-sum test and Kruskal-Wallis one-way ANOVA on ranks were chosen for two-group and three-group comparisons when unequal variance existed. Population differences were considered significant at $p<0.05$ (5).

\section{RESULTS}

All studied pain-relief tablets showed either similar or delayed disintegration in the test beverages in comparison with water. The disintegration times of hydrocodone bitartrate-acetaminophen tablets in whole milk and $2 \%$ milk $(37.15 \pm 2.61 \mathrm{~min}$ and $37.75 \pm 3.90 \mathrm{~min}$, respectively, $n=6$ each) were similar. But they were approximately 6 min longer than the disintegration times of the batches immersed in $1 \%$ and fat-free milk $(31.64 \pm 1.57 \mathrm{~min}, n=6$ and $31.94 \pm 2.26 \mathrm{~min}, n=8$, respectively). The disintegration times of hydrocodone bitartrate-acetaminophen tablets were shorter in calcium-fortified orange juice, commercial iced coffee, and regular Coca-Cola ( $27.56 \pm 2.32 \mathrm{~min}, 17.78 \pm 0.96 \mathrm{~min}$, and $12.05 \pm 1.63 \mathrm{~min}$, respectively) than in milk, but longer than in water $(9.99 \pm 0.65 \mathrm{~min}, n=6$, Table $1 \mathrm{~A}$ and Figure $2 A)$. Similarity, the disintegration time of ibuprofen tablets in $2 \%$ milk was longer than that in water (14.01 $\pm 1.92 \mathrm{~min}$, $n=6$ vs $7.08 \pm 1.24 \mathrm{~min}, n=3$, Table $1 \mathrm{~B}$ and Figure $2 \mathrm{~B}$ ). The disintegration time of tramadol $\mathrm{HCl}$ tablets was longer in $2 \%$ milk (10.42 $\pm 1.40 \mathrm{~min}, n=4)$, but was similar to that in regular Coca-Cola and in water $(7.41 \pm 0.88 \mathrm{~min}, n=6$, and $6.49 \pm 0.14 \mathrm{~min}, n=3$, respectively, Table $1 \mathrm{C}$ and Figure $2 \mathrm{C}$ ). Disintegration of hydrocodone bitartrate-acetaminophen and ibuprofen tablets in calcium-fortified orange juice was significantly longer than for tramadol $\mathrm{HCl}$ tablets $(27.56 \pm 2.32 \mathrm{~min}$ and $21.65 \pm 4.29 \mathrm{~min}$ vs $4.97 \pm 0.49 \mathrm{~min}$, Table 1A-C).

Disintegration of hydrocodone bitartrate-acetaminophen tablets was significantly delayed in milk (21-27 min longer than in water), calcium-fortified orange juice (17.5 min longer than in water), and commercial iced coffee 
Table 1. Disintegration Times of (A) Hydrocodone BitartrateAcetaminophen 5-mg/500-mg Tablet, (B) Ibuprofen 200-mg Tablet, and (C) Tramadol HCl 50-mg Tablet in $800 \mathrm{~mL}$ of Test Beverages

(A)

\begin{tabular}{lc}
\hline Tested Medium & Disintegration Time (Mean \pm SD) \\
\hline Whole milk & $37.15 \pm 2.61 \min ^{a}(n=6)$ \\
\hline $2 \%$ milk & $37.75 \pm 3.90 \min ^{a}(n=6)$ \\
\hline $1 \%$ milk & $31.64 \pm 1.57 \min ^{a}(n=6)$ \\
\hline Fat-free milk & $31.94 \pm 2.26 \min ^{a}(n=8)$ \\
\hline Orange juice with calcium & $27.56 \pm 2.32 \min ^{a}(n=6)$ \\
\hline Commercial iced coffee & $17.78 \pm 0.96 \min ^{a}(n=6)$ \\
\hline Regular Coke & $12.05 \pm 1.63^{5} \min ^{b}(n=3)$ \\
\hline Water & $9.99 \pm 0.65 \min ^{(n=6)}$ \\
\hline
\end{tabular}

${ }^{a}$ Significant, $P<0.001$, using Kruskal-Wallis one-way ANOVA on Rank ${ }^{b}$ Not significant

(B)

\begin{tabular}{lc}
\hline Tested Medium & Disintegration Time $($ Mean \pm SD) \\
\hline $2 \%$ milk & $14.01 \pm 1.92 \min ^{a}(n=6)$ \\
\hline Orange juice with calcium & $21.65 \pm 4.29 \min ^{a}(n=3)$ \\
\hline Commercial iced coffee & $12.12 \pm 1.92 \min ^{b}(n=3)$ \\
\hline Regular Coke & $11.59 \pm 3.53 \min ^{c}(n=3)$ \\
\hline Water & $7.08 \pm 1.24 \min (n=3)$ \\
\hline
\end{tabular}

aSignificant, $P<0.001$

${ }^{b}$ Significant, $P<0.02$

'Not significant

(C)

\begin{tabular}{lc}
\hline Tested Medium & Disintegration Time $($ Mean \pm SD) \\
\hline $2 \%$ milk & $10.42 \pm 1.40 \min ^{a}(n=4)$ \\
\hline Orange juice with calcium & $4.97 \pm 0.49 \min ^{b}(n=3)$ \\
\hline Commercial iced coffee & $6.13 \pm 0.36 \min ^{b}(n=3)$ \\
\hline Regular Coke & $7.41 \pm 0.88 \min ^{b}(n=6)$ \\
\hline Water & $6.49 \pm 0.14 \min (n=3)$ \\
\hline
\end{tabular}

${ }^{a}$ Significant, $P<0.05$, using one-way ANOVA ${ }^{b}$ Not significant

(approximately $8 \mathrm{~min}$ longer than in water). But the delay in regular Coca-Cola (2 min longer than in water) would probably not be clinically significant. The delay of ibuprofen tablet disintegration in $2 \%$ milk (7 min longer than in water) and in calcium-fortified orange juice (5 min longer than in water) was statistically important, but again, this level of delay will need to be further assessed before claiming clinical significance. The delay of ibuprofen tablet

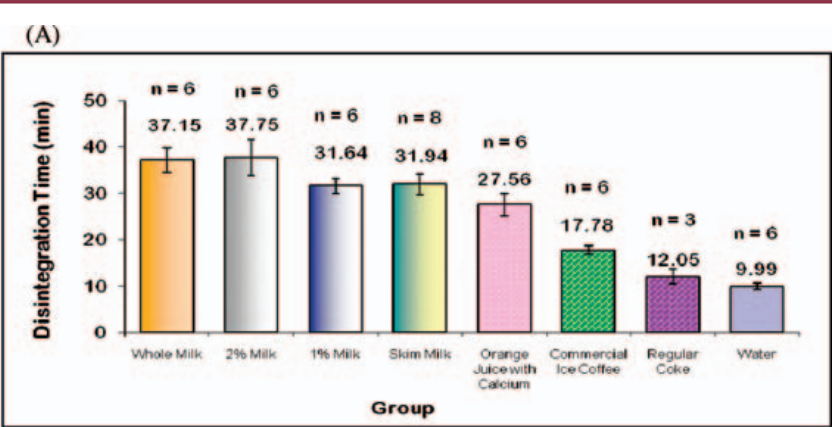

(B)

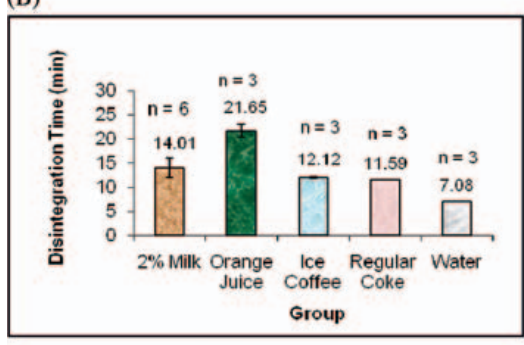

(C)

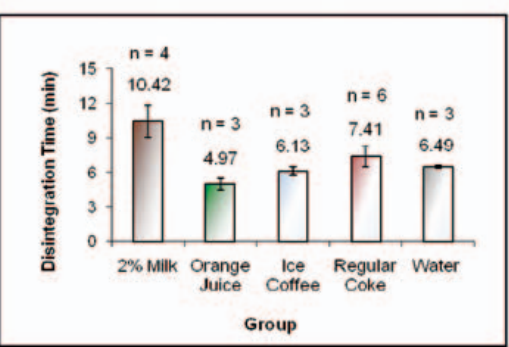

Figure 2. Disintegration times of (A) hydrocodone bitartrate-acetaminophen $5 \mathrm{mg} / 500 \mathrm{mg}$, (B) ibuprofen $200 \mathrm{mg}$, and (C) tramodol HCl in studied beverages and water.

disintegration in commercial iced coffee was significant (14 min longer than in water). For tramadol $\mathrm{HCl}$ tablets, disintegration was statistically delayed only in $2 \%$ milk.

When a USP disk was applied to simulate the foodweight effect exerted on a tablet ingested after a meal, the data indicate that this effect was more prominent in $2 \%$ milk than in $1 \%$ milk. In $2 \%$ milk, the disintegration times of hydrocodone bitartrate-acetaminophen tablets with and without a USP disk were $37.75 \pm 3.90 \mathrm{~min}(n=6)$ and $29.14 \pm 0.67 \mathrm{~min}(n=3)$, respectively. But in $1 \%$ milk, the differences in disintegration times for hydrocodone bitartrate-acetaminophen tablets with and without a USP disk were smaller (31.64 $\pm 1.57 \mathrm{~min}$ and $29.18 \pm 2.29 \mathrm{~min}$, respectively, $n=5$ each, Table $2 \mathrm{~A}$ and Figure $3 \mathrm{~A}$ ). The disintegration time of hydrocodone bitartrate-acetaminophen tablets without a USP disk was longer in $2 \%$ milk than in $1 \%$ milk $(37.75 \pm 3.90 \mathrm{~min}, n=6$ vs $31.64 \pm 1.57$ $\min , n=5$, Table $2 \mathrm{~A}$, Figure $3 \mathrm{~A}$ ), but the times were almost the same when a USP disk was incorporated into the study $(29.14 \pm 0.67 \mathrm{~min}, n=3$ vs $29.18 \pm 2.29 \mathrm{~min}, n=5$, Table $2 \mathrm{~A}$, Figure $3 \mathrm{~A}$ ). When a USP disk was applied to an ibuprofen tablet, its disintegration in water was almost the same as 
Table 2. Disintegration Times of (A) Hydrocodone BitartrateAcetaminophen 5-mg/500-mg Tablets in $800 \mathrm{~mL}$ of $2 \%$ and $1 \%$ Milk and Water, (B) Ibuprofen 200-mg Tablet in $800 \mathrm{~mL}$ of Water, Using a 3.05-g USP Disk to Simulate Food-Weight Effect (A)

\begin{tabular}{lc}
\hline Tested Medium & Disintegration Time (Mean \pm SD) \\
\hline $2 \%$ milk & $37.75 \pm 3.90 \min ^{a}(n=6)$ \\
\hline $2 \%$ milk with a USP Disk & $29.14 \pm 0.67 \min ^{b}(n=3)$ \\
\hline $1 \%$ milk & $31.64 \pm 1.57 \min ^{c}(n=5)$ \\
\hline $1 \%$ milk with a USP Disk & $29.18 \pm 2.29 \min ^{d}(n=5)$ \\
\hline Water & $9.99 \pm 0.65 \min ^{(n=6)}$ \\
\hline
\end{tabular}

Disintegration times in all test beverages were significantly different from that in water

Significant, $P=0.008$ between $2 \%$ milk $^{a}$ and $2 \%$ milk with a disk ${ }^{b}$ Not significant, $P=0.064$ between $1 \%$ milk $^{c}$ and $1 \%$ milk with a disk ${ }^{d}$

(B)

\begin{tabular}{lc}
\hline Tested Medium & Disintegration Time (Mean \pm SD) \\
\hline Water with a USP Disk & $7.08 \pm 1.24 \min ^{\mathrm{a}}(n=3)$ \\
\hline Water & $6.97 \pm 0.19 \min (n=3)$ \\
\hline
\end{tabular}

${ }^{a}$ Not significant, $P=0.88$ using $t$-test

(A)

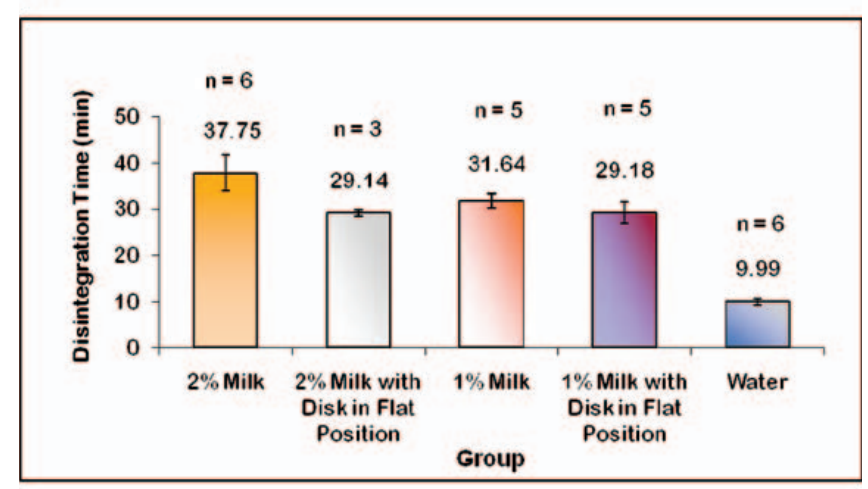

(B)

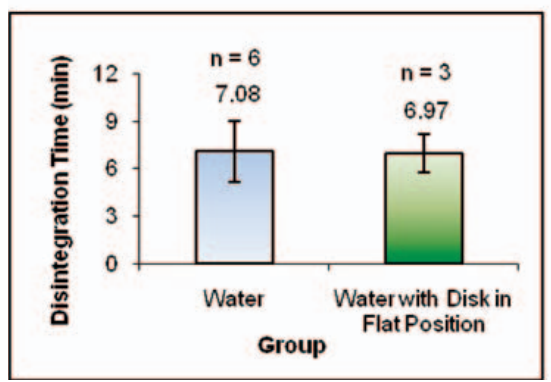

Figure 3. Disintegration times of pain medication with and without a USP disk: (A) hydrocodone bitartrate-acetaminophen $5 \mathrm{mg} / 500 \mathrm{mg}$ and (B) ibuprofen $20 \mathrm{mg}$.
Table 3. Disintegration Times of Hydrocodone BitartrateAcetaminophen 5-mg/500-mg Tablet in Straight 2\% and Straight 1\% Milk and the Hybrid Medium Preparation (0.1 N HCl-milk 1:4)

\begin{tabular}{lc}
\hline Tested Medium & $\begin{array}{c}\text { Disintegration Time } \\
\text { (Mean } \pm \text { SD) }\end{array}$ \\
\hline $800 \mathrm{~mL} \%$ milk & $37.75 \pm 3.90 \min ^{\mathrm{a}}(n=6)$ \\
\hline $640 \mathrm{~mL} \%$ milk in $160 \mathrm{~mL} 0.1 \mathrm{~N} \mathrm{HCl}$ & $15.50 \pm 1.22 \min ^{\mathrm{b}}(n=6)$ \\
\hline $800 \mathrm{~mL}$ fat-free milk & $31.94 \pm 2.26 \min ^{\mathrm{c}}(n=6)$ \\
\hline $640 \mathrm{~mL}$ fat-free milk in $160 \mathrm{~mL} 0.1 \mathrm{~N} \mathrm{HCl}$ & $16.46 \pm 0.65 \min ^{\mathrm{d}}(n=3)$ \\
\hline $800 \mathrm{~mL}$ water & $9.99 \pm 0.65 \min ^{(n=3)}$ \\
\hline
\end{tabular}

Disintegration times in all test beverages were significantly different from that in water

Significant, $P=0.002$ between $2 \%$ milk $^{a}$ and $2 \%$ milk with $0.1 \mathrm{~N} \mathrm{HCl}^{b}$

Significant, $P<0.001$ between skim milkc and skim milk with $0.1 \mathrm{~N} \mathrm{HCl}^{d}$

that without a disk $(7.08 \pm 1.24 \mathrm{~min}$ and $6.97 \pm 0.19 \mathrm{~min}$, respectively, $n=3$ each, Table $3 \mathrm{~B}$ and Figure 3B), reflecting a prompt drug-release mechanism achieved by the excipients incorporated in the formulation.

However, use of a straight beverage as the disintegrating medium might not be appropriate for conducting such an experiment, because normal adults produce up to $60 \mathrm{~mL}$ per hour of a basal secretion containing approximately $4 \mathrm{mmol} \mathrm{H}^{+}$. This can rise to more than $200 \mathrm{~mL}$, between 15 and $50 \mathrm{mmol}$ per hour, when maximally stimulated (6). Because $800 \mathrm{~mL}$ of medium in a 1000-mL low-form glass beaker is required to conduct a disintegration study, a hybrid medium of $160 \mathrm{~mL}$ of $0.1 \mathrm{~N}$ $\mathrm{HCl}$ with $640 \mathrm{~mL}$ of a test beverage was proposed for this study. To examine how medium temperature equilibrates with water temperature in a bath containing $8.5 \mathrm{~L}$ of deionized water maintained at $39.0 \pm 0.5^{\circ} \mathrm{C}$, a 1 - L beaker holding $160 \mathrm{~mL}$ of $0.1 \mathrm{~N} \mathrm{HCl}$ at $39^{\circ} \mathrm{C}$ was placed in the water bath. Six hundred forty milliliters of cold, fat-free milk $\left(6^{\circ} \mathrm{C}\right)$ was poured to the beaker, then a hydrocodone bitartrate-acetaminophen tablet was added to one basket tube, and the USP disintegration apparatus was started. Medium temperature was recorded incrementally until it equilibrated with the water bath temperature. It took 5.5 min to reach $25^{\circ} \mathrm{C}, 10 \mathrm{~min}$ to $30^{\circ} \mathrm{C}, 25 \mathrm{~min}$ to $35^{\circ} \mathrm{C}, 38 \mathrm{~min}$ to $37^{\circ} \mathrm{C}$, and $51 \mathrm{~min}$ to $38.2^{\circ} \mathrm{C}$ (Figure 4). The disintegration time of hydrocodone bitartrate-acetaminophen tablets was next tested in the hybrid medium.

Data indicate that although the disintegration times of hydrocodone bitartrate-acetaminophen tablets in the hybrid medium $(0.1 \mathrm{~N} \mathrm{HCl}$ plus $2 \%$ or fat-free milk) were longer than those in water, they were not as long as tablet disintegrations in straight $2 \%$ or fat-free milk (Table 3 ). The disintegration times of hydrocodone bitartrate-acetaminophen tablets in straight $2 \%$ milk and hybrid $2 \%$ milk were $37.75 \pm 3.90 \min (n=6)$ and $15.50 \pm 1.22 \min (n=3)$, respectively $(P<0.05)$. The disintegration times of hydrocodone bitartrate-acetaminophen tablets in straight skim milk and hybrid skim milk were $31.94 \pm 2.26$ min and 


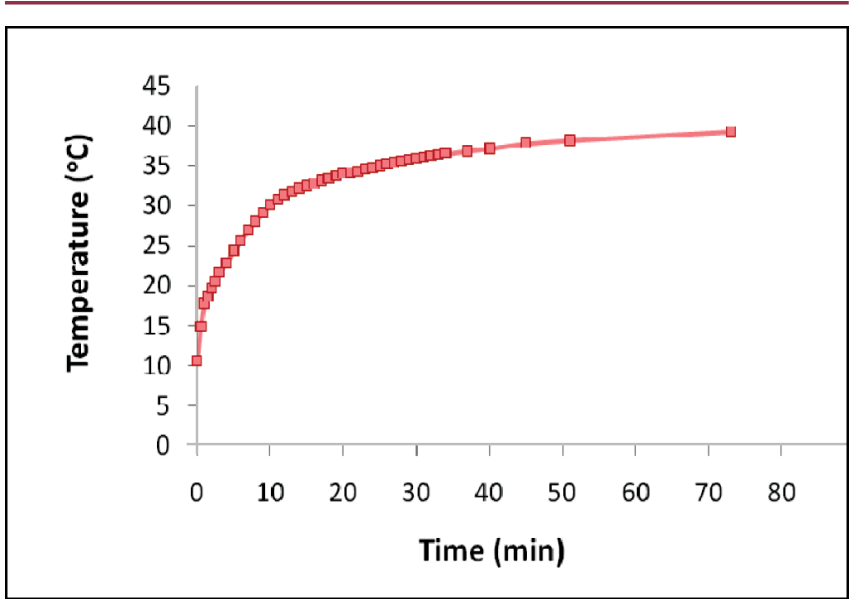

Figure 4. Temperature profile of $640 \mathrm{~mL}$ of cold skim milk at $5^{\circ} \mathrm{C}$ blended with $160 \mathrm{~mL}$ of $39^{\circ} \mathrm{C} 0.1 \mathrm{~N} \mathrm{HCl}$ as disintegration medium in a 8.5-L water bath maintained at $39 \pm 1^{\circ} \mathrm{C}$.

$16.46 \pm 0.65 \mathrm{~min}$, respectively ( $n=6$ each, $P<0.05$, Table 3 , Figure 5). The disintegration times of hydrocodone bitartrate-acetaminophen tablets were very similar in hybrid $2 \%$ milk (15.50 $\pm 1.22 \mathrm{~min}, n=6)$ and hybrid fat-free milk (16.46 $\pm 0.65 \mathrm{~min}, n=6)$, as shown in Table 3 and Figure 5.The disintegration times in the hybrid media were approximately 6 min longer than those in water $(9.99 \pm 0.65 \mathrm{~min}, n=3)$. This statistical difference may or may not have clinical impact. Of potentially greater clinical significance was the unexpected production of resilient foam in both straight or hybrid fat-free milk throughout the test period of the USP disintegration apparatus (Figures 6-8). The extent as well as the duration of foam formation are worthy of attention. Hydrocodone bitartrate-acetaminophen tablets churning in $2 \%$ and $1 \%$ milk produced foam lasting $5 \mathrm{~min}$. Skim milk and $2 \%$ milk foam lasted longer than $30 \mathrm{~min}$, and skim milk with $0.1 \mathrm{~N}$ $\mathrm{HCl}$ foam lasted longer than 15 min (Figure 6). Tramadol tablets churning in hybrid medium $(640 \mathrm{~mL}$ fat-free milk

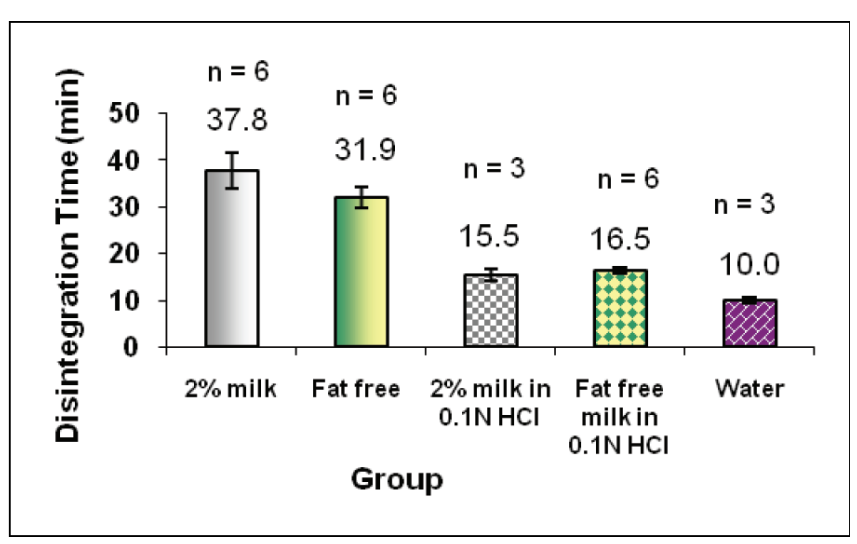

Figure 5. Disintegration times of hydrocodone bitartrate-acetaminophen (5-mg/500-mg) tablet in hybrid media $(640 \mathrm{~mL} 2 \%$ and skim milk in $160 \mathrm{~mL}$ of $0.1 \mathrm{NHCl}$ ).

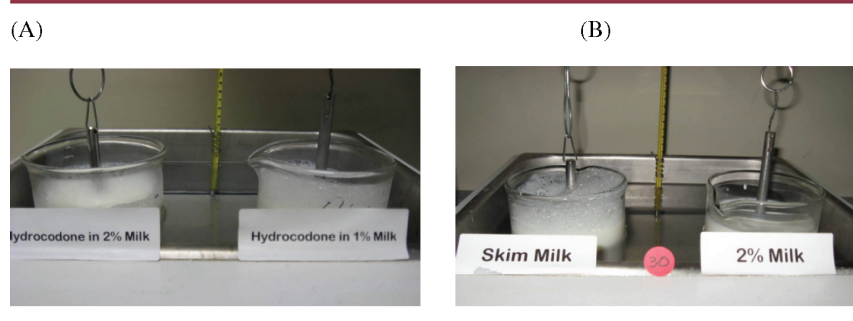

(C)

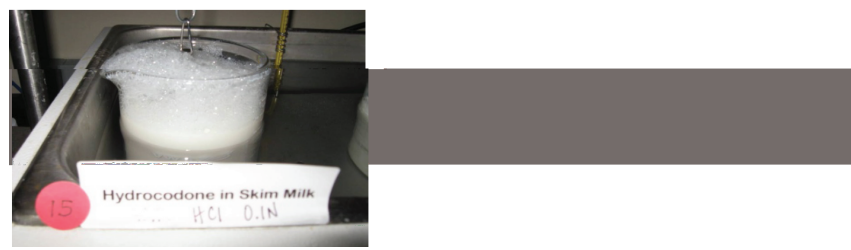

Figure 6. Hydrocodone bitartrate-acetaminophen tablets churning in (A) $2 \%$ and $1 \%$ milk, (B) skim milk and $2 \%$ milk, and (C) skim milk with $0.1 \mathrm{~N} \mathrm{HCl}$.

mixed with $160 \mathrm{~mL} 0.1 \mathrm{~N} \mathrm{HCl}$ ) produced foam lasting more than $7 \mathrm{~min}$ (Figures 7A-C). The foam-formation level for ibuprofen tablets in the fat-free milk $0.1 \mathrm{~N} \mathrm{HCl}$ hybrid medium was low initially, the first two minutes of the dissolution study, which was also the tablet coating dissolution period (Figure 8A). But foam formation was quite notable after the coating layer disappeared and the core tablet disintegrated in the hybrid medium (Figures 8B and $\mathrm{C}$ ). The question next raised was whether the remarkable foam formation was apparatus-design specific.

To address this question, ibuprofen (a coated tablet) and hydrocodone bitartrate-acetaminophen (an uncoated tablet) were tested in the USP dissolution

(A)

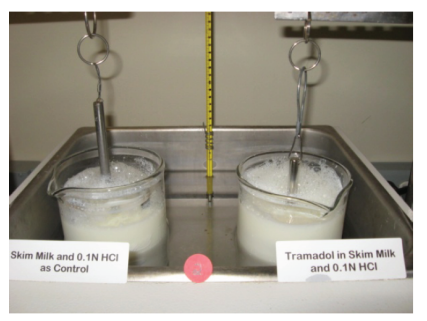

(C)

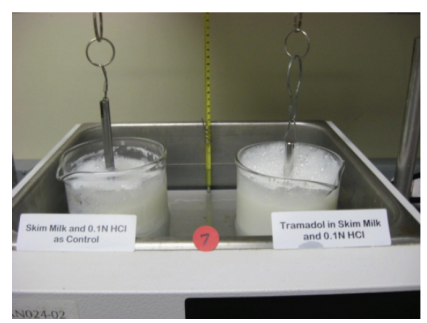

Figure 7. Tramadol HCl tablets churning in hybrid media $(640 \mathrm{~mL}$ fat-free milk mixed with $160 \mathrm{~mL} 0.1 \mathrm{~N} \mathrm{HCl}$ ) showing foam formation at (A) $2 \mathrm{~min}$, (B) $5 \mathrm{~min}$, and (C) $7 \mathrm{~min}$, which was immediately after complete disintegration. The beakers on the left show control hybrid media without tramadol. 
(A)

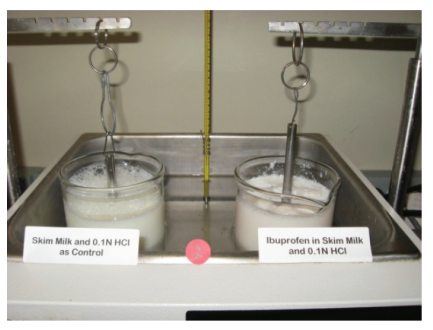

(C)

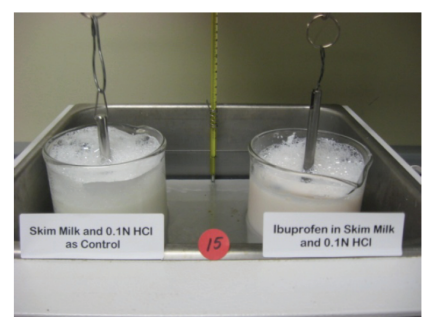

(B)

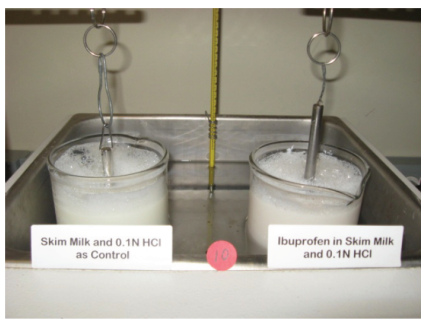

(A)

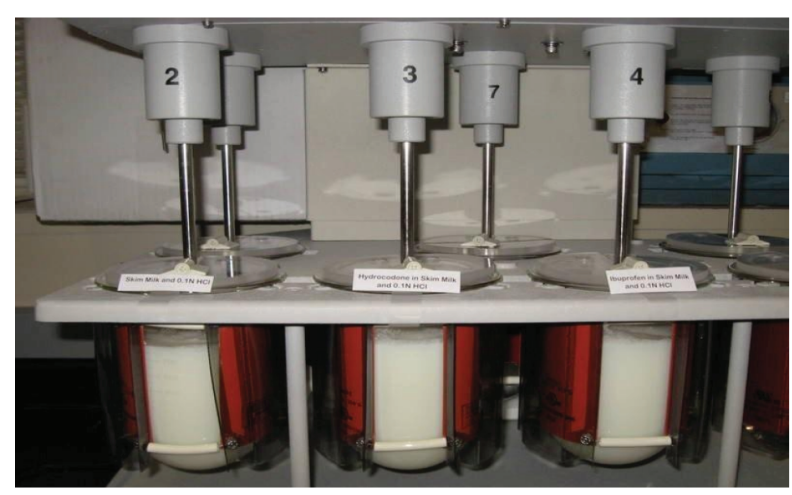

(B)

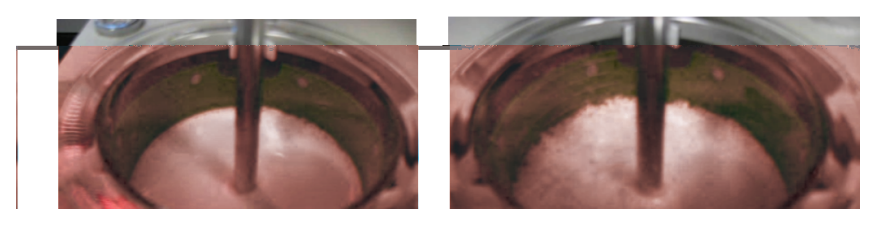

Figure 9. USP dissolution study: (A) hydrocodone (vessel 3) and ibuprofen (vessel 4) in skim milk and $0.1 \mathrm{~N} \mathrm{HCl}$ at $2 \mathrm{~min}$. No drug product in vessel 2 as control. Close-up photos taken at $15 \mathrm{~min}$ to show details with (B) control (vessel 2) and (C) hydrocodone (vessel 3).

During in vitro disintegration studies, fat-free milk exhibited significant foam formation with hydrocodone bitartrate-acetaminophen tablets that lasted for more than 30 min with straight fat-free milk (Figure 6A) and more than 15 min with hybrid fat-free milk (Figure 6C). Similar foam formation was noted with tramadol tablets (Figure 7). If such in vitro behavior correlates in vivo, drug molecule transport to the stomach wall may be hindered. Since little foam was observed initially with ibuprofen tablets until the coating layer dissolved (Figure $8 \mathrm{~A}$ ), and the overall foam formation was less (Figures $8 B$ and $8 C$ ), it was speculated that the coating composition might have functioned as a defoaming agent. The addition of a USP disk to simulate a food-weight effect on the disintegration of an immediate-release tablet revealed that food weight is not an important parameter in such a dosage form because the tablet already has a built-in disintegration mechanism to release drug molecules promptly to alleviate pain. The $0.1 \mathrm{~N} \mathrm{HCl}$ hybrid fat-free milk exhibited remarkable foam formation with hydrocodone bitartrateacetaminophen and tramadol in the disintegration apparatus for more than 15 min. Raising and lowering the basket of the disintegrating device was speculated to facilitate foam formation by increased air contact with the fat-free milk. Foam was not as significant in USP dissolution Apparatus 2 using fat-free milk and $2 \%$ milk whether the paddle was stirred at $75 \mathrm{rpm}, 100 \mathrm{rpm}$, or $150 \mathrm{rpm}$. showed delayed disintegration in orange juice, but not tramadol $\mathrm{HCl}$.

Hydrocodone bitartrate-acetaminophen tablet disintegration was delayed in all studied beverages except regular Coca-Cola. There was 17.5-min delay of this product in calcium-fortified orange juice, the second most acidic beverage in the study. Combined effects from excipient-beverage interaction and beverage viscosity may account for this observation. 


\section{CONCLUSIONS}

Neither the USP disintegration apparatus nor the dissolution apparatus is an ideal device for studying food and beverage effects. Foam formed with all studied pain medications in fat-free milk during in vitro disintegration studies (Figures 6-8), but to a lesser degree in the dissolution studies. The churning motion of a disintegrating device more closely resembles gastric contractions; in addition, air is constantly swallowed during talking and food intake and passed out of the body. Although patients are often counseled to take medications, especially painrelief medications, with milk to decrease the potential for gastric irritation, this study shows that milk delays disintegration of all three products (Table 3 and Figure 5). Since an IR pain medication is designed to have prompt onset of action, patients should be made aware of any factor that hinders drug molecule transport to the absorption site. It may be advisable to take these IR pain medications with water until more information on the administration of drugs with beverages and food is available.

\section{REFERENCES}

1. Davies, P. Oral Solid Dosage Forms. In Pharmaceutical Preformulation and Formulation, 2nd ed.; Gibson, M., Ed.; CRC Press LLC: Boca Raton, FL, 2004; p 379.

2. Chuong, M.; Poirier, B.; Crosby, S.; Pidgeon, C. A Modified USP Disintegration Method to Simulate a Tablet Disintegrated in the Stomach When Taken with Cold Beverage or with Food. AAPS J. 2007, 9 (S2), 1687.

3. Ibuprofen tablets. USP package insert. Interpharm Inc.: Hauppauge, NY; 2000.

4. Disintegration $\langle 701\rangle$. In United States Pharmacopeia and National Formulary USP 31-NF 26; The United States Pharmacopeial Convention, Inc.: Rockville MD, 2008, p 266.

5. Zar, J. H. Biostatistical Analysis, 4th ed.; Prentice Hall: Upper Saddle River, NJ, 1998; pp 80-81.

6. Washington, N.; Washington, C.; Wilson, C. G. The Stomach. In Physiological Pharmaceutics: Barriers to Drug Absorption, 2nd ed.; Taylor and Francis: New York, 2001; p 80. 